\title{
Middle Level Leadership in Chinese Universities in a Time of Change
}

\author{
*Jinyu Feng, Xudong Sun \\ China University of Petroleum-Beijing, China \\ jinyufeng@cup.edu.cn
}

\begin{abstract}
This study explored leadership in higher education based on the researchers' interpretation of the perspectives of a specific group of participants, which refers to middle level academic leaders (MLL) and an interrogation of leadership literature. There are 32 respondents in total including, deans of faculties, associated deans, heads of schools, associated heads and teachers. The major findings of the research are the multiple conceptions of leadership and educational reforms influence on leadership, which have been identified by examining the importance of the roles and current status of MLLs within the university, the activities undertaken by MLLs and the relative importance of those activities, the ambiguities, conflicts and pressures to which MLLs are subject. A key outcome of the investigation is the tension it revealed between how these academic middle level leaders perceive their management roles against their perceptions of their roles as academics. The research also indicated that the multiple conception of leadership from respondents was strongly influenced by traditional Chinese culture. Meanwhile, the recent higher education reforms affected the leadership styles of MLLs, i.e. the potentially further development of collective leadership.
\end{abstract}

Keywords: Higher Education, China, Middle level academic leader, Educational Reform, Collective leadership

\section{Introduction}

Higher education around the world has been experiencing rapid and unprecedented changes over the last quarter century. As Ramsden (1998) indicated that the fundamental change was from an elite system of higher education, largely confined within national boundaries, to a mass higher education system in global business. Numbers, finances, structure, purposes, students, governance, technologies, the amount of available knowledge and its diversity have all changed. These largely external factors have had and will continue to have huge consequences for how universities are run, what university staff do and how academic leaders work. Chinese Higher Education has continued to evolve. Over the past two decades, universities in China have some remarkable changes, such as great expansion in university students, amalgamations of universities, reform of funding sources, administration reforms and new models of university management, have raised the challenges for university leaders at all levels, which are reflected in many researchers' studies (Duan, 2001; Mok, 2005; Hare and Thomas, 2002; and Yang, 2000).

When leadership is mentioned in higher education, attention is immediately focused on the people who are in senior administrative or academic positions. However, leadership happens at all levels in institutions. Foskett and Lumby (2003) point out that, no matter what formal organizational charts may indicate leadership may be undertaken by a number of people at different levels of the organization. Bennet and Anderson (2003) support this position and suggest that leaders can be found in various parts of institutions. Their emphasis is on the group of people who are in formal positions such as heads of departments, the socalled 'middle leaders'. This position is mostly explored in the realm of school leadership in the literature but it has increasingly received attention in other education sectors (Newton, 2002; Clegg, 2003). The focus of this study is on middle level leaders in Chinese Higher Education Institutions (HEIs).This paper in tends to explore the meaning of leadership in current Chinese HEIs based on the perspectives of the Middle Level Leaders (MLLs), which therefore will contribute to the leadership literature.

\section{Literature Review}

The topic of this study: Middle level leadership in Chinese Universities in A Time of Change, brings together three broad areas of interest: leadership, higher education organizations and higher education reform. Each of these areas could be investigated from a variety of approaches resulting in a variety of intersections. The purpose of this section is to review the published literature on leadership and how it applies to the study and the practice of leadership. This section begins by introducing the concepts of leadership in general, then reviewing different theories of leadership related to education both in Western and Chinese literature perspectives. Stogdill (1974) reviewed over 3000 studies directly related to leadership and sug- 
gested that there are almost 'as many different definitions of leadership as there are persons who have attempted to define the concept' (p.7). There is no singular, all embracing definition of leadership in the literature, and this also applies to educational leadership. The conceptual confusion within the general area of leadership studies is compounded for educators by several factors, such as disagreement about conceptual unity or conceptual pluralism (Howe, 1994). There is no precise agreement as to what educational administration is, whether educational leadership is a subset of educational administration (Mintzber, 1973), whether the two are essentially the same (Hodgkinson, 1991), or whether or not 'leadership', 'administration' and 'management' are conceptually distinct terms. Moreover, while some scholars attempt to distinguish the terms and to define 'leadership' precisely (Greenfield, Marshall \& Reed, 1986), others argue that 'leadership' is a vague term encompassing both administration and management and that 'leadership is administration' (Hodgkinson, 1991). Nevertheless, many researchers would agree with the following propositions (Howe, 1994, p.3277):

- Leadership is not coercion or obtaining compliance to decisions, rules, regulations, or policies by means of coercion

- Leadership involves an influence relationship between leaders and followers with the intent of realizing change, accomplishing mutual purposes, or creating shared meaning

- Leadership involves interaction with people rather than, or at least in addition to, engaging in technical aspects of work

- Leadership is shaped by personal, organizational and environmental factors and their interaction, and results in various outcomes, with improvement of the 'technical core'- curriculum and instruction-being the most important outcome

As Middlehurst (1992) argued it is difficult to separate the roles and tasks of leadership from each other in higher education, but it is important to conceptually separate the roles of leadership from those of management. Otherwise the longer-term focus and more intangible aspects of leadership may not be given sufficient attention under the pressures on management. The definition of leadership adopted in this study is interpersonal influence, directed through communication towards personal and organizational goal attainment and a shared vision (Bass, 1990; Dubrin, 2001). Traditional leadership scholars developed theories that were concerned with the peripheries of leadership, such as traits, personality characteristics, and whether leaders are born or made (Eddy \& VanDerLinden, 2006). Although the importance of leadership in education is now widely accepted by teachers, researchers and policy makers, it is only recently that the field of educational leadership has developed in its own right. Initially education adopted and adapted leadership theory from other fields such as history, political science, sociology, psychology and business management. Leadership theories relating to education have regularly changed in focus as each previous one failed to produce a satisfactory explanation of the factors involved in the complex process. A new era of leadership research, which is directly applicable to the educational context, was the work of Burns (1978). In distinguishing between transactional and transforming leadership, Burns highlighted the importance of the group and moral aspects of leadership, which are critical in education. Transactional leadership due to Burns is primarily concerned with negotiation between individuals in an institution and does not result in change to purpose or the resources of the institution. Transformational leadership, on the other hand, is concerned with the common goals of the group and results in a change to both purpose and resources. An increasing awareness of the importance of social relations in the leadership contract, the need for a leader to be given authority by their followers and a realization that no one individual is the ideal leader in all circumstances have given rise to a new school of leadership thought. Refer to as 'shared', 'collective' or 'distributed' leadership, this approach argues for a less formalized model of leadership. Distributed leadership implies a different power relationship, where distinctions between leaders and followers are blurred. It offers a more inclusive view of organizational life whereby individuals, groups and teams at all levels within the institution collectively influence strategic direction.

Gronn (2000) provides us with examples of distributed leadership in situations in which anyone working in higher education would be familiar with such as the relations between executives and their personal assistants and between organizational heads and their immediate subordinates. The significance of such relationships will have different meanings to different people depending on how convinced they are of the phenomenon of distributed leadership. MacBeath et al. (2004), study which is set in the school context, identified six forms of distributed leadership (see table 3.3): (1) formal distribution (via hierarchical structures); (2) pragmatic distribution (via ad hoc delegation to meet demands and challenges); (3) strategic distribution (based on the planned appointment of individuals to contribute positively to the development of leadership in the organization); (4) incremental distribution (devolving more responsibility as people demonstrate their ability to lead); (5) opportunistic distribution (people willingly extending their roles and 
taking initiative to lead); and (6) cultural distribution (leadership is assumed rather than given, shared organically and opportunistically and is embedded in the institutional culture). Compared with massive works on educational management and administration in Chinese academia, very few works deal explicitly with leadership (Lu, 1999; Song, 2001; Wang, 1998). Some scholars (e.g. Feng, 2002; Zhang, 1998) have argued that educational leadership is still at the early stage of development and heavily dependent upon Western general or business management theories. The knowledge base and systematic theoretical framework for educational leadership have not been adequately developed. Many contemporary Chinese academics have indicated insufficient empirical studies have been conducted in this field in China (Xiao, 1986; Wu, 2000; Tang, 1999).

A literature review of related educational management in Chinese sources (Feng, 2011) indicates that there tends to be conceptual confusions among Chinese scholars. The concept of leadership is viewed as synonymous to that of management. Leadership and management are not considered as two conceptually different terms although more recent some scholars have explored the differences between them (Huang \& Cheng, 2001; Wu et al, 2000). They are interlocking concepts in administration discourse, and this can in turn lead to confusion and tension in it. In the minds of some Chinese scholars, there is not a clear theoretical distinction between the two concepts but an amalgamation of related ideas and hybrid conceptions. Chinese scholars generally agree that leadership is at the highest level of management, mainly focusing on macro level policies and decision-making. There are three levels in an organization: leaders, managers, and operators. Unlike western leadership literature fraught with complexity and confusion about the concept of leadership (Howe, 1994), the general agreement is reached that both leadership and management are not mutually exclusive but overlapping to some extent, even though some scholars attempt to distinguish leadership from management. Many western scholars tend to clarify the difference and similarities between these two terms. These two concepts are considered as having more similarities than differences in Chinese management and leadership literature.

\section{Methodology}

The general overall approach that it has been taken in this study is perhaps best described as interpretivist'. This means that the underlying assumptions are that reality is socially constructed and is subject to individual interpretation. Therefore objective 'truth' cannot be the ultimate goal, instead, in the interpretive paradigm, the complexity of behavior and experience is described and analyzed in context, using actor accounts and theorizing emerges to an extent from what is observed rather than by imposing a priori frameworks which are subsequently tested (Robson, 2002). Interpretive research methods are typically qualitative in nature which allows for the complexity and ambiguity of individual experience. Accordingly it was used qualitative research methods in this study which are discussed later in the following parts. Given the intention to understand middle level leaders (i.e. heads of schools and deans of faculties) interpretations of their roles, understanding of their responsibilities and experience of their managements, the inquiry is based on the assumption that reality is socially constructed (Berger \& Luckmann, 1966) and that people respond to their constructed reality. The study thus rejects the objectivist stance of positivism.

In this study, purposive sample was used to choose research sites and participants. Purposive sampling according to Kerlinger (1973) is characterized by the use of judgment and a deliberate effort to obtain representative samples by including presumably typical groups in the sample. In purposive sampling, instead of taking a random cross section of the population to be studied, small numbers of people with specific characteristics, behavior or experience are selected to facilitate broad comparisons between certain groups that the researcher thinks likely to be important (Walker 1985, p30). The purposive sampling for institutions was four Ministry of Education-directed universities from which the interviewees were selected. The chosen research sites were determined by three criteria: 1) geographic location; 2) Institutional Administrative body; 3 ) Accessibility to the researcher. The sampling of participants of this study is purposive as well The participants were selected because of their professional occupation and working status.

Qualitative researchers have generally expressed difficulty in negotiating access to research sites and participants to conduct their studies (Kvale, 1996; Marshall and Rossman, 1999). In the event a couple of people refused to take part, either because of the research is far different from their academic interests or because of their time unavailability. In contradistinction to western Universities which enjoy a more open and freely access to academics from external individuals, Universities in China seemed more closed to 'outsiders' of their academic community. This close nature of Chinese Higher Institutions might have also contributed with the low rate response to the invitations to join the study. In total there were 32 inter- 
views completed, including the pilot study. These 32 respondents included 12 deans, 7 associate deans and 13 academic respondents. The academic respondents included professors and lecturers. Two techniques of data collection were adopted, i.e. interview and documentary analysis for this research. The qualitative interview using semi-structured open-ended questions enabled the researcher to obtain the perceptions and accounts of middle level academic leaders in Chinese higher education institutions. The analysis of documents from the websites of universities can provide an insight into some of the documented leader roles, practices and policies.

\section{Results and Discussion}

One of the main research interests of this study is to explore the MLL's perspectives on the meaning of leadership: how they define leadership and how they regard themselves as leaders. The responses from the participants in this study indicate very multiple conceptions of leadership. Their understanding and interpretations of leadership reflected all together strong influence of Chinese traditional leadership concept, traditional leadership theories as well as current new leadership style in Western leadership theories. The following part starts the discussion with the traditional leadership styles and then moves on to summarize the complex picture of leaders' understanding of leadership.

Hierarchical leadership: Almost all the participants of this study expressed the concept of hierarchical and bureaucratic leadership in current higher education in China. They agreed to the idea that power and positions are invariably linked to leadership. Respondents tended to consider a leader as a person who has power in a hierarchy and exercises it in a directive manner. In other words, a leader is supposed to use one's official power to transmit predetermined aims and objectives in a strictly hierarchical structure. The common descriptors in this conception are 'head', 'director', 'organizer', 'guide', and 'decision-maker'. The concepts like 'accomplishing tasks' and 'directing followers to a set goal' were also heavily emphasized. Respondents generally placed a strong emphasis on the authoritative and unquestioned role of leaders. This view was shared across all sampled institutions, faculties and schools. For instance, a leader was considered as one who 'holds the official position', 'head of an institution who has power and privilege', or the 'director of a formal organization'. A leader was also viewed as 'an organizer or a boss who directs followers to accomplish certain tasks'. Participants of this study both MLL and academics, emphasized leadership as a topdown implementation process. In the process of accomplishing tasks, the strict rules and regulations are supposed to be imposed rigidly and the exercise of strict control and scientific management is emphasized. Respondents tended to regard a good leader as one who can manage human and physical resources well and accomplish tasks in workplaces. There seemed to be a clear division between the leaders who propose a plan and followers who implement this plan. This suggests that a leader who has power bestowed by an official position is supposed to manage others. The relationship between a leader and followers tends to focus on controlling and obeying.

Our respondents admitted the strong influence of Chinese leadership traditions on their ideas in general. Some criticized traditional overemphasis on task orientation and neglect of the wills of followers. These comments suggest a strong bureaucratic culture in educational systems. Decision-making power tended to belong to leaders rather than staff while consultation and delegation were often neglected in practice. It should be noted that the respondents tended to use 'traditionally' or 'generally speaking' to indicate this conception. This suggests that respondents may operate from inherited Chinese traditions and from their own individual experiences and expectations. Moreover, some were critical of this inheritance. However, many respondents suggested the inherited thinking has inevitably influenced their conceptions of leadership, which places an emphasis on positional power and authority. This study suggests that the notions of directive, solitary and instrumental leadership focus on task accomplishment. Such emphasis on positional power in Chinese leadership traditions shares similarities with the Western bureaucratic and hierarchical leadership concepts that flourished in the early twentieth century (e.g. Talyor, 1996). It seems that many respondents in this study still held conceptions of leadership as positional power or scientific management. This conception has its limitations as it overemphasizes order, control, and hierarchy in leadership processes. Although respondents expressed the hierarchical leadership concept, this study also clearly suggested the development and preference of collective leadership among MLL and their colleagues. This will further illustrated in the following section.

Towards collective leadership: Although the majority of the respondents of this study reckoned the existence of traditional leadership styles in the contemporary higher education environment in China, they also expressed the preferences of collective leadership, especially for the middle level academic leaders. Some of 
the interviews even reflected some MLL have developed collective leadership within their own faculty or school. Among 19 MLL in this study, 16 declared their leadership as 'in service of others'. These MLLs all used the words 'servant' or 'service' to describe their leadership. Middle managers portraying themselves as servants or, more elaborately as in service of others have been reported in other research. 'Being a servant to academic colleagues' refers to MLL assist academic staff to achieve their career goals by providing opportunities and environment for them. Henkel (2000) pointed out 'staff career development was perceived as an important and welcome aspect of their (heads) role' (p.38). The MLL in this study expressed their satisfaction of facilitating career development of their colleague, mostly young academic staff. In their mind, to help the development of their academic staff is to help the discipline development of their own faculty, which is one of vital management goals for most MLLs.

In addition to the servant leadership, another term mostly used by MLL and their academic staff to describe the leadership of middle level is named as 'team leadership'. Team or collective leadership primarily focuses on the process of a group of leaders in an organization working as a team to make decisions and facilitate achievement of organizational goals. Members of the leadership team rely on their collective wisdom and reach consensus in decision-making. Collaboration and consultation within a team of leaders are emphasized. Thus, in this conception it seems to be more appropriate to consider team leadership as teamwork among leaders who hold official positions in an organization. Respondents generally stressed cooperation within a team of leaders and tended to equate their notion of team and collective leadership with 'democratic leadership'. This view was common across all the respondents. It should be noted this concept of 'team leadership' is different from the one discussed in western leadership literature. The western notion of team leadership emphasizes that every one working in a team takes on leadership roles depending on their ability and skills. It is not dependent upon formal leadership structures (Gronn, 2000). The team members may not hold official positions in an organization while team members in Chinese leadership team are often those who have authority and positional power. In other words, the power of decision-making mainly lies in a team of leaders rather than ordinary organizational members. The key element in team leadership conceptions in China is primarily power and authority related to a group of people who hold official positions.

Informal distributed leadership: In our study, we have little evidence of presence of incremental, opportunistic or culture distribution; in addition, these three elements of MacBeath's study can be generally categorized into a new category called informal distribution, where leadership is distributed either outside the university system or not via hierarchical structures. Based on the number of samples of our study, we use four categories of distributed leadership: (1) formal distribution, e.g. devolution of financial and administrative authority to faculties; (2) pragmatic distribution, e.g. division of responsibilities between deans of faculties and heads of departments; (3) strategic distribution, e.g. employing professor from other universities to bring new skills, knowledge and funding; (4) informal distribution, e.g. a research group or project. By using the above four categories, we summarized by number of respondents, the perceptions towards leadership distribution. Although most of deans and heads admitted there is an evident leadership distribution via hierarchical structures, informal distribution shows the highest representation in our study.

All of our MLL within different universities expressed they have more power than before, in terms of finances and personnel. MLL also expressed an extra working load and more responsibilities brought by power delegation. For instance, one dean from Na Min University concluded: 'at present the university is gradually delegating the power to faculties and departments. In reality, the process of delegating is not only that the power is delegated but also the extra responsibilities are also delegated into faculties and departments' 'In other words, in the past there were many difficult issues faced by the university leaders. Now, it's our job to deal with them'. He continued to give one example about the staff salary within his faculty: '...Because it (salary) is related to everyone's personal benefits, including the rules of improving one's position salary, how to define the level of position bonus in the future. This is our major task at the present and also it is the most difficult issue to handle.' The dean continued: 'power delegation has some advantages to my work, however, if I can't use it well, it will bring some unnecessary troubles for my work.'

On contrast to more shared leadership from institution level to faculty and school level, there is a big disagreement within this study towards devolving shared leadership to the level below them. For instance, teachers from He Dong University commented they cannot feel the differences. They still just conducted teaching tasks which have assigned to them without any pre-consultation. One reason is the power delegation from faculty and school level to the level below them is largely depended on the individual dean of the faculty or the head of school. Some deans are quite happy with their 'hands off'; While other heads 
expressed difficulties to lose their control, power and responsibility to other members. Among these 'hands on' heads, some do not have sufficient trust on others and some are too conscious about the accomplishment of the work. Some deans do believe that they should protect their academic staff from involving these administrative tasks and concentrate on their own research and teaching. In summary, power has been delegated better between institutional and middle academic unit level than it within faculties and schools. The development of distributed or shared leadership distributed or shared leadership indeed depends on the context, individual and culture of one single faculty or school.

Table 1: Leadership Distribution

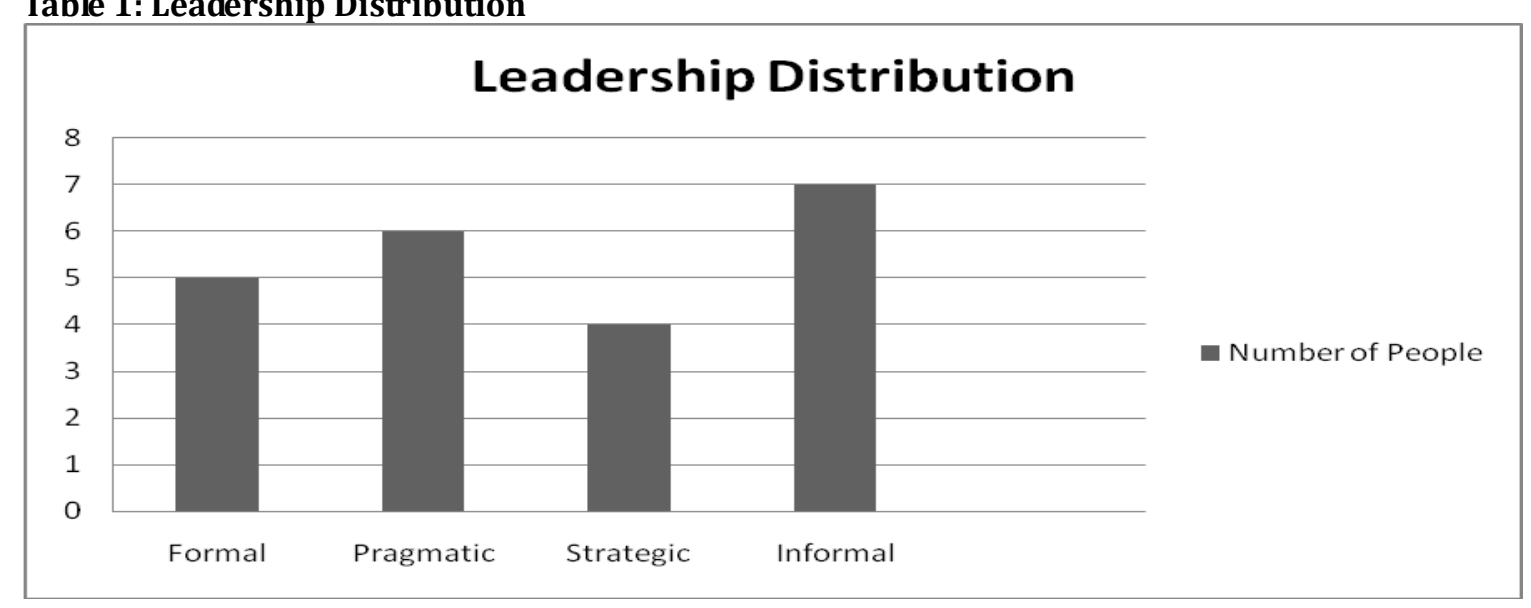

Leadership role vs. Academic role: Currently, MLLs in Chinese Universities carry out their leadership roles at the same time as to fulfill their academic roles as mentors for graduate students or researchers. Dean Hao Jiantin from He Dong University, who has a long working experience in industrial world, proposed that a MLL could be a full-time professionalized or part-time pluralistic. Most respondents agreed that academic reputation and academic career are the required background of academic leader, especially for those dealing with academic affairs. But as associate head Ma Dashuai from Tong Jian university pointed out that once he/she becomes a more administrative leader, the primary duty is to carry out his/her administrative responsibility. Other administrative duties occupied most of MLLs' daily working time. Playing two roles at the same time has some potential difficulties. First, as soon as there are conflicts between administrative affairs and academic affairs in a leader's work, he/she may be inclined to his/her academic affairs. In some important decisions, he/she may favor his/her discipline. Head Hu Juntao pointed out:

'This may cause partiality in work. Even if the leader does not show partiality, people will doubt the fairness of a decision.'

Furthermore, professor Wang pointed out that some leaders may intentionally use their executive authority to capture more research resources. Second, when a leader gets involved in academic affairs, or transmits his/her executive authority into academic authority, he/she would choose the academic development of his/her own faculty or school. It is easy for him/her to be seen as the academic authority because of his executive position. In other words, positional power prevails in the leadership roles. Thus, few people feel free to express their different academic ideas commented by associate professor Jiang Nantian, associate progessor Pang Xiliang and associate professor Zhou Jielun. It should be noticed that this view was shared more among the junior academics rather than their senior counterparts. Third, as professor Nan Batian said:

'academic leaders mat spend too much time attending academic conferences internationally and domestically, causing the administration to be operated inefficiently'

However, most respondents disagreed that leaders should work full-time in administration without an academic career. First, if a leader has no academic specialty, after he leaves his administration position, there is no suitable job for him. Second, with a higher academic reputation, it is easier for a MLL to deal with other academic leaders. Professor Wang Leijie pointed out that communicating with the teachers may be more difficult without a higher academic reputation. Third, as some leaders were promoted to leadership position, their academic development was interrupted. 


\section{Conclusion}

The research question of this study asked about 'what does leadership mean according to middle level leaders at this time'. On the contrary to the researcher's initial thought that the study will offer a straight forward response, there is no definite answer which can be provided to this research question. In as far as elucidating the general issues, it concurs with general leadership literature about ambiguity and uncertainty around leadership concepts as pointed out in the previous section. The complex reality of respondents' understanding towards the meaning of leadership is beyond the researcher's primary expectation. Respondents' interpretation of leadership presented a multiple notion rather than the prevailing of a single concept. The multiple conception of leadership from respondents was strongly influenced by traditional Chinese culture. Meanwhile, the recent higher education reforms affected, as predicted from the beginning of research design, the leadership styles of MLLs, i.e. the potentially further development of collective leadership. There are, of course, some authors who would prefer to claim differently and offer concise definitions. The offering of this study is a conceptualization of leadership as constructed from the researcher's interpretation of the respondents' views and researcher's reflections on the literature.

There are 3 significant leadership styles within this study: hierarchical leadership, collective leadership and informal distributed leadership. The respondents' beliefs about leadership were often related to positional power and hierarchical structure. This finding is congruent with the observations and analyses in previous studies about Chinese leadership traditions (e.g. Bush \& Qiang, 2000; Chen, 2002; Child, 1994, Hofstede, 1991, 1994; Ling et al, 2000; Miles, 1999). Within these traditional leadership styles, respondents regarded decision-making, command, control and management as the major functions of leaders. Although traditional leadership is the mostly mentioned concept, collective leadership have been emphasised by the respondents in this study as well. They have expressed different understandings towards collective leadership and termed it as servant leadership, teamwork leadership and distributed leadership. The conceptual focus on leadership of our respondents' shifted from task and directive orientations to motivation and collaborative orientations. Leadership came to be regarded as an influence, a democratic awareness, an empowerment ideology and a collaborative relationship. Leadership came to be viewed as a dynamic, interactive and multi-level process of achieving shared vision or common goals. Respondents who agreed with collective leadership tended to believe that leadership can be dispersed at various levels in the institution. However, many interviewed MLLs indicated the tensions existing in their workplaces between the traditional Chinese orientation and Western orientation, which is top-down implementation and participative decision making. They also indicated their dilemmas in addressing these issues, for example, on one hand, many respondents claimed that collective leadership would inevitably become a predominated trend in China in the near future; and on the other hand, they commented on strong cultural influences, environmental constraints and resistance. The above comments suggest that change towards collective leadership will be an incremental and slow process in China.

In summary, respondents in this study generally reported several notions of leadership simultaneously. Sometimes the conceptions reported were contradictory. The research findings of the study indicate that respondents may hold several conceptions simultaneously. MLLs in this study also reported that they would utilize different leadership styles selectively according to different situations. It was beyond the scope of this research to focus specifically on examining why participants had more than one conception of leadership. Exploration of the occurrence of multiple conception of leadership would be interesting theme for further study as it is one indication of the complexity of leadership. The research findings of this study suggest that MLLs' conceptions about leadership were heavily shaped and influenced by the surrounding environment.

\section{Reference}

Bass, B. M. S. (1990). Handbook of leadership: theory, research, and managerial applications (3nded.), New York: The Free Press.

Bennett, N. \& Anderson, L. (2003). Rethinking educational leadership: challenging the conventions: Sage Publications Ltd.

Berger, P. \& Luckman, T. (1966). The social construction of reality, London: Penguin Books.

Burns, J. M. (1978). Leadership, New York: Harper \& Row.

Clegg, S. (2003). Learning and teaching policies in higher education: mediations and contradictions of practices. British educational research journal, 29, 804-819.

Duan, X. (2001). Chinese higher education enters a new era, Academe. City, pp. 1-8. 
Dubrin, A. (2001). Leadership: research findings, practice, and skills, Boston: MA: Houghton Mifflin Company.

Eddy, D. \& VanDerlinden, L. (2006). Emerging definitions of leadership in higher education: New visions of leadership or same old hero leader? Community College Review, 34(1), 5-26

Feng, D. (2002). Ershi shiji jiaoyu guanli lilun fazhan zhi fansi (Reflections on the theory developemnt in educaitonal administration in the 20th century), Shanghai: Shanghai jiaoyu chubanshe (Shanghai Education Press) (In Chinese).

Feng, J. (2011). Educational middle level leadership in China, PhD thesis, University of Bristol

Foskett, N. H. \& Lumby, J. (2003). Leading and managing education: international dimensions: Sage Publications Ltd.

Gronn, P. (2000). Distributed Properties: a New Architecture for Leadership. Educational Management and Administration, 28(3), 317-338.

Hare, P. \& Thomas, H. (2002). Reforms in Chinese higher education and their effect on teacher education in inner Mongolia. Compare, 32(2), 193-196.

Henkel, M. (2000). Academic Identities and Policy Change in Higher Education, London: Jessica Kingsley.

Hodgkinson, C. (1991). Educational leadership: the moral art, Albany, NY: SUNY Press.

Howe, W. (1994). Leadership in education administration, in T. Husen and T. N. Postethwaite, (eds.), The international encyclopaedia of education. Oxford: Pergamon, pp. 3276-3284.

Kerlinger, F. N. (1973). Foundations of Behavioural Research, London, New York, Sidney,

Kvale, S. (1996) Interviews. An introduction to qualitative research interviewing, Thousand Oaks, London: Sage Publications.

Lu, K. (1999). Xiaozhangxue (Principalship), Beijing: Huawen chubanshe (Huawen Publishing House). (In Chinese).

MacBeath, J., Oduro, G. K. T. \& Waterhouse, J. (2004). Distributed leadership in action: a study of current practice in schools, Nottingham: National College for School Leadership.

Marshall, C. \& Rossman, G. B. (1999). Designing qualitative research (3rd), Thousand Oaks: CA: Sage.

Middlehurst, R. \& Elton, L. (1992). Leadership and management in higher education. Studies in Higher Education, 17(3), 251-264.

Mintzberg, H. (1973). The nature of managerial work, New York: Harper \& Row.

Mok, K. H. (2005). Globalization and educational restructuring: university merging and changing governance in China. Higher Education, 50, 57-88.

Newton, J. (2002). Barriers to effective quality management and leadership: case study of two academic departments. Higher education, 44, 185-212.

Ramsden, P. (1998). Learning to lead in higher education, London: RoutledgeFalmer.

Song, D. (2001). Lingdao kexue shiyong jiaoxue gaiyao (Practical teaching outline on leadership), Beijing: Dangjian duwu chubanshe (Dangjian Reader Publishing House). (In Chinese).

Stogdill, R. M. (1974). Handbook of leadership: a survey of theory and research, New York: The Free Press.

Taylor, R. (1996). Greater China and Japan: prospects for an economic partnership in East Asia, London: Routledge.

Tang, L. (1999). Woguo shaiqinian lai putong jiaoyu gunli zhi fenxi (Analysis on genreal education management research for the past 17 years). Shanghai jiaoyu keyan (Shanghai education research), 4.

Wang, L. (1998). Lingdaoxue: lilun shijian yu fangfa (Leadership: Theories, Practices and Methods), Guangzhou: Zhongshan daxue chubanshe (Zhongshan University Press). (In Chinese).

Wu, Z. (2000). Jiaoyu xingzhengxue (Education administration), Beijing: Renmin jiaoyu chubanshe (Remin educational publishing house) (In Chinese).

Wu, Z., Feng, D. \& Zhou, J. (2000). Xinbian jiaoyu guanlixue (New Education Management). City: Huadong shifan daxue chubanshe (East China Normal University Press) (In Chinese): Shanghai.

Xiao, Z. (1986). Ping Jiaoyu Lilun Yanjiu Zhong De Mouxie Qingxiang (Comments on certain tendencies in education theory research). Kengcheng jiaocai jiaofa (Curriculum, course materials and pedagogy), 4 .

Yang, R. (2000). Tensions between the global and the local: a comparative illustration of the reorganisation of China's higher education in the 1950s and 1990s. Higher education, 39, 319-337.

Zhang, X. (1998). Chinese perspectives on western concepts of educational leadership in Xi'an, China in the era of Deng Xiaoping, Brigham Young University. 